\title{
Prevalence of Cybersex in India
}

\author{
Satyanarayana Reddy Alla ${ }^{1 *}$, Ambujam $\mathrm{G}^{2}$ \\ ${ }^{1}$ Consultant in Fertility and Sexual Medicine, Apollo Fertility, Hyderabad, India \\ ${ }^{2}$ Department of General Surgery, -Vinayaka Missions, Medical College and Hospital, \\ Vinayaka Mission Research Foundation (Deemed to be University), Karaikal
}

\begin{abstract}
Internet has become a part of our lives. Two-thirds of adult men and one third of females use internet in India. In that, $12 \%$ of websites are pornographic, 30\% of net traffic is sex-related, $35 \%$ of downloads are of pornographic material. In India, $72 \%$ of adult males and $28 \%$ of adult women viewed pornography. One-third of people accessed the net for porn while in office or in school/college. In a study done on college students in a small town in South India, $84.2 \%$ view porn on a daily basis, one-half felt that they use porn more than they intended to see and were awake late at night; two-thirds felt that their academic grades dropped. On a multicity sex survey in South India on college students-69\% watch, sex videos 6 hours a week; 24\% of girls feel porn is harmless; $30 \%$ of students had sex relations with lovers, and 12\% of girls became pregnant. In an objective assessment of porn consumption in medical students in Central India, $14 \%$ of boys and $8 \%$ of girls were found to have the potential to become internet sex addicts. Cybersex addiction is six times more in men than in women. In the self-claimed hypersexual people, porn consumption was 6 times higher, total sexual outlets per week was three times higher, total sexual partners was double when compared with non-hypersexual people.
\end{abstract}

Keywords: Cybersex, Cybersex addiction, Hypersexuality, Internet, online sexual activities, Online sex problems, Porn.

\section{Introduction}

The growth of the internet in the past seven years has been phenomenal. Before 1993 the Internet was used by only a few persons in laboratories and universities. In 2001 there will be over 94 million users. Also increasing is the number of people who are drawn into using Internet access to obtain sexual satisfaction. Most of these people are "recreational users," analogous to recreational drinkers or gamblers, but a significant proportion have pre-existing sexual compulsions and addictions that are now finding a new outlet [1]. A 32-year-old cybersex addict in Bengaluru allegedly spent around Rs.80, 000 in one month to get access to webcam models. How I escaped an X-rated life: A 56-year-old woman on moving the court and asking for porn websites to be blocked. Her strongest argument is That her story of her life and marriage, wrecked by violence and abuse [2]. Porn addiction in adolescents rising. Despite the porn ban, India is the 3rd-largest porn watcher with $30 \%$ female users. India is hungry for some free-to-access porn, with the third-largest appetite in the world [3]. After porn ban, Hyderabad records 75 percent the increase in porn viewing. Rising porn addiction in Indian youth worrying. How India became one of the top porn-watching countries in the world [4]. This news clipping from the mainstream news and from lifestyle magazines shows the extent of pornography prevalence in India. Craving, loss of control of the amount and frequency of use, compulsion to use despite negative consequences, dependence, and 
withdrawal effects are the basic components of addiction. Dependence on substances like alcohol, nicotine, illicit drugs is traditionally considered an addiction. It is well recognised that some behaviours also can be addictive. Shopping, internet usage, gaming, gambling, even work, eating, exercise also can be addictive. Porn addiction and sex addiction are also included in the list. Behaviour addictions are also called process addictions. Substance addiction and behaviour addiction have similar neural, biochemical pathways [5].

Internet usage has increased exponentially in this century. What constitutes normal use, excessive use, addiction to internet is not defined. It is the use of internet or is it the usage of content of the internet search that is to be considered for calling it internet addiction is not clear. More than $30 \%$ of online searches and more than $35 \%$ of internet downloads are sexrelated [6]. Online Sex Activity (OSA) is the usage of internet for sexual activity. The usage can be through text, audio, video, or interactive modes. The sexual activities may have the purpose of education, exploration, recreation, support, treatment, gratification, or commercial [4].

Cybersex is a subcategory of online sexual activities. It is using internet for sexual gratification such as reading, writing, viewing, showing sex content; chatting, participating in sex acts like masturbation, interactive sex actions; acquiring new sex partners, accessing old partners online to offline, offline to the online continuation of sex affairs [7]. Online Sex Problems (OSP) are difficulties that arise because of engaging in online sexual activities. These include sexual, psychological, relational, family, social, occupational, and financial problems [8].

Online Sex Addiction (OSA)/ Cybersex Addiction/ Problematic Cybersex/ Problematic Online Pornography Usage (POPU): problematic cybersex is defined as an uncontrolled and excessive involvement in online sexual activities associated with-- A)
Persistent desire or unsuccessful efforts to stop, reduce or control cyber sexual behaviours; B) Persistent and intrusive cybersex related thoughts and obsessions (cognitive salience); C)Using cybersex for mood regulation purposes; D) Occurrence of negative mood states when cybersex is (withdrawal); E) Need for more hours of use or for new sexual content (tolerance); Negative consequences [9]. Only three criteria are common in these three different concepts, namely-a) loss of control; b) excessive time dedicated to sexual behaviours; c) significant negative consequences [10].

Sexual behaviour is vastly heterogeneous, and the practices range from sexual fantasy, solitary sex like masturbation, partnered sex to sexual violence. To define what is excessive sex is difficult. More than seven orgasms a week is hypersexual. This varies widely with different individuals, in different age groups, in different time frames in the same age group, different practices, solitary and partnered, consistency of the frequency, variability with different partners [11].

Focusing on quantity rather than the problem, distress, consequences of excessive sex behaviour is not viable. The other terms to denote hypersexuality are Sex Addiction; Compulsive Sex Behaviour; Sexual Impulsivity; Hypersexual Disorder, Out of Control Sexual Behaviour. The Practice of this hypersexual behaviour online is cybersex addiction. So, cybersex addiction is a major subcategory of compulsive sexual behaviour [12].

DSM- 5 and ICD-11 hypersexuality, internet addiction, porn addiction, porn-induced sexual dysfunction is clinically identified for a quartercentury. None of these are recognised as separate clinical entities. Diagnostic Statistical Manual- 5 (DSM-5) reclassified the gambling disorder from impulsive control disorder to a behavioural addiction. Internet gaming disorder was included in section 3--emerging measures and models [13]. 
The clinical condition of compulsive sexual behaviour, cybersex addiction, is not included in DSM-5 -for want of sufficient evidence to warrant its inclusion. A diagnostic entity called compulsive sexual behaviour disorder is being included in the upcoming edition of International Classification of Diseases- 11 (ICD-11) in the impulsive control disorder section [14].

\section{Materials and Methods}

The data search examines 26 journal papers that were obtained electronically through major scientific databases such as PubMed, Google Scholar, Scopus, IEEE, and Science Direct, which were searched using sets of keywords. The keywords used were cyber-sex, hypersexuality, internet addiction, and India. Literature searching included an internet search engine, targeted mass media websites, newspapers, and social media [15].

\section{Results and Discussion}

\section{Internet Usage in the World and in India}

Internet has become an integral part of our lives. Internet is the prime mode of education, information, communication, and business today. There are 4.6 billion internet users in the world, making a penetration rate of $60 \%$. In 2020 , there are 56.4 million internet users in India making a penetration rate of $43 \%$ [16]. Excluding children of less than 14 years of age, the penetration rate is $63 \%$. Two-thirds of people above 18 years of age are accessing internet in India.

This penetration rate is increasing. Five years ago, the penetration rate was $27 \%$, and today, it is almost 50\% [17]. It is going to increase for a few more years and afterwards reaches a plateau. Female users are $33 \%$ of the total internet users, with an implication that more than two-thirds of the adult males have access to the net. A decade ago, accessing the net was almost equally distributed between net cafes, personal computers, and mobile phones.
Now $90 \%$ of access to the net is by mobile phones in India [18].

Porn is everywhere on the net. $12 \%$ of all websites are pornographic, but $30 \%$ of traffic over the net is porn. Porn receives more regular traffic than Netflix, Amazon, and Twitter combined. 35\% of internet downloads are porn related. Porn is a 100-billion-dollar industry. 40 million Americans regularly visit porn sites. In the USA, $87 \%$ of males between $18-35$ years of age are watching porn at least weekly, and $29 \%$ of women in the same age group are viewing porn at least once a week. 3.9 billion people in the world are watching porn regularly [19].

Most of the porn consumption is for recreational purposes only, and the percentage is difficult to estimate. In India, $72 \%$ of adult men and $28 \%$ of adult women viewed pornography. The amount of porn usage by men is relatively more than by women. So, the total amount of porn used by men is 6 times more than that used by women [20].

One-third of people accessed the net for porn in the workplace or in educational institutions. In addition to the usage of the net, the trend of viewing the shared porn clips over social media, among groups, among friends increased the porn viewership disproportionate to net usage. The average time spent per session of porn viewing is around 10 minutes all over the world and 8 minutes in India [21]. The obvious deduction is even though the number of people accessing porn is two thirds, the percentage of people accessing on a regular basis, say once in a week, is far less, and the time spent overviewing porn is far lesser, and usage of porn for purposes other than for recreation is least. This is the reason for porn-induced sexual dysfunctions being less in public.

A study was done on the pattern of internet usage by medical students in Central India, not on selected or opted students, but on all students. Based on the symptoms of internet addiction, $9.1 \%$ of boys and $10.2 \%$ of girls were diagnosed as internet addicts. 


\section{Cybersex Usage Pattern}

The motivations for online sexual activity as described by [21] are -distraction $81 \%$; coping $57 \%$; pursuing sexual activities that could not be done offline $43 \%$; educational purposes $25 \%$; socialisation $16 \%$; meeting offline partners $12 \%$; meeting offline dates $9 \%$; getting support for sexual concerns $8 \%$; buying sexual material $6 \%$ [22].

In a study done on female college students of a psychology class in the USA. The students are in 18-29 years age group. One-third view porn more than once a week, and $7 \%$ view porn on a daily basis. In this group of women, the average lifetime sexual partners (partners involved in not only penetrative vaginal sex but also in Oro-genital sex) is 5.23, the range being $0-82$. It is significant that in non-regular porn users, the average number of lifetime sex partners is 4.66, and in the heavy users of porn, the average number of lifetime sex partners is 20.14. It is to be analysed - whether A) girls with more sexual interest are involved in both more porn usage and more sexual partners; B) Usage of more porn is making them have more sex partners; C). Porn usage is complimentary to sex or substitute for sex or is it enhancing sexual activity [23].

In a study done on university students by an online questionnaire in four countries Canada, Germany, Swedan USA. The lifetime prevalence of A). Getting online sexually stimulatory material was $76 \%$; B). $30.8 \%$ had some cybersex activity; C). $14.1 \%$ used cybersex for finding offline sex partners [24].

In the same study, in the same users, in the past three months, when assessed in a scale of 0 to 6 , zero is never, 6 is daily usage of cybersex-it was found that A). Getting online sexual excitatory material-2.44; B). Having cybersex 0.81 ; C). Finding offline sex partners 1.27 and D). Paying or being paid for online sex services 1.6. In non-users, payment for online sex services in a scale of 0-6 was 0.02 only compared to 1.6 in porn users. For sexual minorities, the lifetime risk is 10 times more, and the frequency is twice for cybersex. In the same study, in the university students- average age 25 years-comparison between different countries.

Table 1. Country Wise Comparison

\begin{tabular}{|l|l|l|l|l|l|}
\hline Country & Sweden & Germany & Canada & USA & Total \\
\hline $\mathrm{N}=$ & 874 & 1021 & 516 & 279 & 2390 \\
\hline Number of sex partners last year & 1.66 & 1.38 & 1.87 & 1.58 & 1.59 \\
\hline Masturbation frequency* & 3.28 & 4.06 & 3.50 & 3.35 & 3.62 \\
\hline Oral, Vaginal, Anal sex* & 3.11 & 3.05 & 3.16 & 2.52 & 3.04 \\
\hline
\end{tabular}

*Frequency measured in 0-6 scale, 0 being never and 6 being daily

In a study done on college-going rural youth in a small town in south India- on a random sample of 853 students - A). One-third visited the net centre for porn now or earlier, and others use mobiles; B). $84.2 \%$ view porn on a daily basis. Of these $50 \%$ felt that they viewed longer than they intended to view and were awake late for porn viewing; C). 39\% exchanged porn with friends and D). 64.7\% reported that their academic performance dropped. In another study done on 5800 students in 272 colleges in 4 states in South
India- representative sample in the colleges but mostly located in metros and urban places-A). Boys start seeing porn at 14-15 years of age; B). $69 \%$ watch 6 hours of sex videos per week; C). $36 \%$ of college students watch violent porn, including rape; D). $48 \%$ of students watch teen porn; E). $34 \%$ of girls in degree college's view porn, and they watch 5 hours of porn videos per week; F). 24\% of girls told porn is harmless; G). Rural students use $10 \%$ less porn, Bangalore; $\mathrm{H}$ ), $30 \%$ of students have sex relations with lovers, and $12 \%$ of the 
girl students got pregnant in graduate life and had a termination of it; I). $25 \%$ of boys visited prostitutes; J). In Bangalore, a metro city with the highest software employee density- $84 \%$ of boys and $91 \%$ of girls said watching oral/anal porn inspires them to try it out [25].

Another classical study was done on 300 medical students in western rural Maharashtra in 2018. A Self-administered Internet Sex Screening Test (ISST) was done on all. In boys, $21 \%$ were low risk, $65 \%$ were vulnerable, and $14 \%$ were at highest risk for the development of internet sex addiction. In girls--73\% were low risk, $19 \%$ were vulnerable, and $8 \%$ were at highest risk for the development of internet sex addiction. Of these medical students, 49\% masturbated while viewing online porn; $24 \%$ of boys and $13 \%$ of girls, total of $37 \%$ indulged in inline sex chat. $9.8 \%$ have sexualised names at online sex chat, implying that most of them had sex chat with their GF/BFs; only $19 \%$ with strangers online.

In a study on university students in Malaysia to assess the effect of religiosity on cybersex, the results show; A) Strong negative effect of religiosity on cybersex engagement; B) Risky behaviour positively associated with more frequent engagement of cybersex [26].

[21] did a study online about self-reported sexual behaviour on a large sample of 9255 with a mean age of 34 years. They are selfidentified that they are:

1. Non sex compulsives-7728-83.5\%,

2. Moderate sex compulsives-1007- $11 \%$

3. Sexually compulsive- $424-4.6 \%$

4. Cyber sexually compulsive- $96-1 \%$.

The time spent on the net was 5 hours for non-sex compulsives, and cyber sexually compulsive people spent 20 hours a week on the net, mostly for sex. Cybersex groups has a preference for chat rooms-43\% males and $70 \%$ females. Self-reported sexual problems were in $6 \%$ of cybersex users [27]. In a study done in Germany by an online sample of self-claimed hypersexual people average age 33.4 years A).
Porn consumption last week was 6.64 hours in men and 1.05 hours in women; B). Fantasies of coercive sexual behaviour was in $60 \%$ for men and $30 \%$ for women; C). Actual coercive sex was done by $20 \%$ of men and $4 \%$ of women; D). In these self-claimed hypersexual men, the total sexual outlets in the past week were 2.64 for partnered sex and 7.87 for masturbation; E). Whereas in self-claimed hypersexual women, the total sexual outlet with partner in the past week was 1.55 and masturbation in the past week was $3.01 ; \mathrm{F}$ ). The total number of sexual partners in the past one year in these selfclaimed hypersexual men were 6.01 and for hypersexual women were 2.77 [28].

Sex addiction: compulsive sex behaviour in the world varies between men and women and the criteria used for identifying compulsive sexual behaviour. It ranges between 1-4\%. Cybersex addiction was 6 times more in men than in women. Till now, no systematic study was done in India on hypersexuality, cybersex addiction, and cybersex-induced sexual dysfunctions. Indian Council of Medical Research (ICMR) in 2013 estimated that sex addiction in India was $0.2 \%$; in men $0.3 \%$ and $0.1 \%$ in women.

\section{Conclusions}

In India, internet penetration reached 50\%. $84 \%$ of boys and $34 \%$ of girl college students in India watch porn on a regular basis. $14 \%$ of male students and $8 \%$ female students are vulnerable for internet sex addiction. Sex addiction in India is $0.2 \%, 0.3 \%$ in men and $0.1 \%$ in women.

\section{Acknowledgement}

I thank my guide Dr. K. Sivarami Reddy for his guidance in preparing the article. I also acknowledge the technical help rendered by my research assistant Dr. Suganya Kannan.

\section{Conflict of interest}

The author has no conflict of interest. 


\section{References}

[1] Gunter, B., 2015. News and the Net. Routledge. [2] Young, K.S. and De Abreu, C.N. eds., 2010. Internet addiction: $\mathrm{A}$ handbook and guide to evaluation and treatment. John Wiley \& Sons.

[3] Khanna, N., 2018. Sexual abuse of children-a legal study in relation to child pornography.

[4] Gautam, A., 2018. Pornistan: How to survive the porn epidemic in India. Readomania.

[5] Young, K.S., 2004. Internet addiction: A new clinical phenomenon and its consequences. American behavioral scientist, 48(4), pp.402-415.

[6] Wolak, J., Mitchell, K. and Finkelhor, D., 2007. Unwanted and wanted exposure to online pornography in a national sample of youth Internet users. Pediatrics, 119(2), pp.247-257.

[7] Cooper, A., Griffin-Shelley, E., Delmonico, D.L. and Mathy, R.M., 2001. Online sexual problems: Assessment and predictive variables. Sexual Addiction \& Compulsivity: The Journal of Treatment and Prevention, 8(3-4), pp.267-285.

[8] Eleuteri, S., Tripodi, F., Petruccelli, I., Rossi, R. and Simonelli, C., 2014. Questionnaires and scales for the evaluation of the online sexual activities: A review of 20 years of research. Cyberpsychology: Journal of Psychosocial Research on Cyberspace, $8(1)$.

[9] Laier, C., Pekal, J. and Brand, M., 2014. Cybersex addiction in heterosexual female users of Internet pornography can be explained by gratification hypothesis. Cyberpsychology, Behavior, and Social Networking, 17(8), pp.505511.

[10] Wéry, A. and Billieux, J., 2017. Problematic cybersex: Conceptualization, assessment, and treatment. Addictive behaviours, 64, pp.238-246.

[11] Walkowitz, J.R., 2013. City of dreadful delight: narratives of sexual danger in late-Victorian London. University of Chicago Press.

[12] de Alarcón, R., de la Iglesia, J.I., Casado, N.M. and Montejo, A.L., 2019. Online porn addiction: What we know and what we don't - A systematic review. Journal of clinical medicine, 8(1), p.91.

[13] Weinstock, J., and Rash, C.J., 2014. Clinical and research implications of gambling disorder in
DSM-5. Current addiction reports, 1(3), pp.159165.

[14]Potenza, M.N., 2014. Non-substance addictive behaviours in the context of DSM-5. Addictive behaviours, 39(1).

[15] Webster, J., and Watson, R.T., 2002. Analyzing the past to prepare for the future: Writing a literature review. MIS quarterly, pp. xiii-xxiii.

[16]Fusilier, M. and Durlabhji, S., 2005. An exploration of student internet use in India: the technology acceptance model and the theory of planned behaviour. Campus-Wide Information Systems.

[17] Mitra, S. and Rana, V., 2001. Children and the Internet: Experiments with minimally invasive education in India. British journal of educational technology, 32(2), pp.221-232.

[18] West, D.M., 2015. Digital divide: Improving Internet access in the developing world through affordable services and diverse content. Centre for Technology Innovation at Brookings, pp.1-30.

[19] Paul, P., 2007. Pornified: How pornography is transforming our lives, our relationships, and our families. Macmillan.

[20]King, S.A., 1999. Internet gambling and pornography: Illustrative examples of the psychological consequences of communication anarchy. Cyber Psychology and Behaviour, 2(3), pp.175-193.

[21]Cooper, A., Delmonico, D.L. and Burg, R., 2000. Cybersex users, abusers, and compulsives: new findings and implications. Sexual Addiction \& Compulsivity: The Journal of Treatment and Prevention, 7(1-2), pp.5-29.

[22] Green, B.A., Carnes, S., Carnes, P.J. and Weinman, E.A., 2012. Cybersex addiction patterns in a clinical sample of homosexual, heterosexual, and bisexual men, and women. Sexual Addiction \& Compulsivity, 19(1-2), pp.77-98.

[23] Schneider, J.P., 2000. A qualitative study of cybersex participants: Gender differences, recovery issues, and implications for therapists. Sexual Addiction \& Compulsivity: The Journal of Treatment and Prevention, 7(4), pp.249-278.

[24]Döring, N., Daneback, K., Shaughnessy, K., Grov, C. and Byers, E.S., 2017. Online sexual 
activity experiences among college students: A fourcountry comparison. Archives of sexual behaviour, 46(6), pp.1641-1652.

[25]Ebiraj, K. and Subramani, R., 2018. Impact of social media among university students of two Metros of South India. Research Journal of Humanities and Social Sciences, 9(1), pp.229-234.

[26] Brindha, D., Jayaseelan, R. and Kadeswaran, S., 2021. Women and Pornography: A Voyeuristic Perspective with Special Reference to Coimbatore. Journal of Psychosexual Health, p.26318318211016990.
[27] Rettenberger, M., Klein, V. and Briken, P., 2016. The relationship between hypersexual behaviour, sexual excitation, sexual inhibition, and personality traits. Archives of sexual behaviour, 45(1), pp.219-233.

[28] Klein, V., Jurin, T., Briken, P. and Štulhofer, A., 2015. Erectile dysfunction, boredom, and hypersexuality among coupled men from two European countries. The journal of sexual medicine, 12(11), pp.2160-2167. 